\title{
PENGARUH SUHU DAN WAKTU TERHADAP GINGEROL PADA JAHE (ZINGIBER OFFICINALE) DENGAN EKSTRAKTOR BERPENGADUK
}

\author{
Indriyana Putri Arifianto, Dwi Handayani, Ilyas Teguh Pangestu*, Rosian Oktavian dan \\ Kresna Suryadi \\ Program Studi Diploma III Teknik Kimia, Departemen Teknologi Industri Sekolah Vokasi, \\ Universitas Diponegoro \\ Jl. Prof. Soedarto, Tembalang, Kota Semarang, Jawa Tengah 50275 \\ "Email: ilyaspangestu26@gmail.com
}

\begin{abstract}
ABSTRAK
Jahe (Zingiber officinale) adalah salah satu jenis rempah rempah yang tergolong dalam suku Zingiberaceae yang telah digunakan secara luas di dunia baik sebagai bumbu dapur maupun sebagai obat medis terhadap penyakit-penyakit ringan. Bagian utama dari jahe yang digunakan adalah rimpang. Produk olahan jahe yang dapat dikembangkan adalah oleoresin jahe yang mengandung komponen gingerol, shogaol, zingerone, resin dan minyak atsiri. Ginger oleoresin berkisar antara 3,2-9,5\%, sedangkan kandungan gingerol dalam oleoresin antara 14-25\% dan shogaol di oleoresin antara 2,8-7,0\%. Mempertimbangkan manfaat jahe yang mengandung antioksidan tinggi yang berfungsi sebagai anti-inflamasi dan mencegah pertumbuhan tumor, perlu untuk mengekstraksi rimpang jahe untuk menentukan jumlah gingerol yang diekstrak. Tujuan dari penelitian ini adalah untuk menentukan faktor yang paling berpengaruh pada ekstraksi gingerol dari rimpang jahe dengan ekstraktor berpengaduk dan kondisi yang relatif baik. Dalam penelitian ini, percobaan dilakukan dengan berbagai suhu $\left(60^{\circ} \mathrm{C}, 80^{\circ} \mathrm{C}\right.$, dan $\left.100^{\circ} \mathrm{C}\right)$ dan waktu 30 menit dan 60 menit. Kandungan Gingerol diukur dengan analisa menggunakan spektofotometer VIS. Analisis hasil pengaruh suhu menunjukkan bahwa hasil ekstraksi 500 gram bubuk Jahe menggunakan 8 liter air sebagai pelarut yang paling optimal adalah dengan suhu $100^{\circ} \mathrm{C}$.
\end{abstract}

Kata Kunci: ekstraksi, jahe, gingerol, spectrofotometer, suhu

\section{PENDAHULUAN}

Jahe (Zingiber officinale Rosc) merupakan herba kronis, akar berserat, dan termasuk monokot. Morfologi Jahe pada umumnya terdiri dari struktur rimpang, batang, daun, bunga dan buah (Banerjee, 2015). Produk olahan jahe yang bisa dikembangkan yaitu oleoresin jahe yang mengandung komponen gingerol, shogaol, zingerone, resin dan minyak atsiri. Rimpang Jahe mengandung oleoresin sekitar 3,2-9,5\%, dengan kadar gingerol berkisar 14-25\% gingerol, 2.8-7\% shogaol (Ramji,2007). Gingerol, shogaol, dan paradol adalah senyawa aktif yang terkandung dalam jahe yang mempunyai sifat anti-inflamasi, antioksidan, antibakteri, dan anti-platelet (Onyenekwe, 1999). Efek gingerol yaitu penenang, analgesik dan antibakteri secara in vivo dan in vitro (Williams dan Lamprecht, 2008). Jahe juga mengandung sejumlah minyak esensial di akarnya. Selain itu, mengandung bahan kimia lain seperti seskuiterpenoid dan monoterpernoid dalam jumlah yang lebih kecil (Vernin, G et al., 2004). Kandungan gingerol yang rendah dalam ekstrak jahe, diperoleh dari proses ekstraksi konvensional biasanya berhubungan dengan degradasi termal, karena gingerol adalah senyawa termolabile (Agarwal, 2001). Untuk menghasilkan minyak jahe dalam proses destilasi konvensional memerlukan waktu berkisar 10-18 jam, yang merupakan sebuah proses yang meningkatkan risiko degradasi termal gingerol (Hu et al., 2011).

Untuk mengekstrak kandungan Gingerol yang terkandung dalam jahe dilakukan dengan ekstraksi menggunakan pelarut. Ekstraksi merupakan proses dengan menggunakan pelarut untuk memisahkan suatu zat yang terkandung pada bahan padat atau cair. Bahan pelarut harus mempunyai kemampuan untuk mengekstrak zat yang diinginkan tanpa melarutkan bahan lainnya. (Guenther, E. 1947). Ekstrak gingerol dapat mengalami dehidrasi, selama penyimpanan dan pengolahan, untuk membentuk shogaol yang sesuai. Studi yang dilakukan sejauh ini terutama difokuskan pada aktivitas gingerol bilier untuk anti-inflamasi (Balladin et al., 1997). Mekanisme ekstraksi gingerol adalah sebagai berikut: pelarut aquadest berdifusi menjadi padatan (bubuk jahe), kemudian zat terlarut (ekstrak gingerol) larut dalam pelarut. Larutan yang bercampur 
dengan pelarut kemudian berdifusi keluar dari padatan, pelarut dicampur dengan zat terlarut berdifusi ke permukaan luar partikel. Pemindahan pelarut biasanya terjadi lebih awal ketika partikel untuk pertama kali dihubungi dengan pelarut (Geankoplis, 1993).

Faktor-faktor yang mempengaruhi ekstraksi adalah suhu operasi, kecepatan pengadukan, ukuran, bentuk, dan kondisi partikel padat, jenis dan jumlah pelarut. Peristiwa fisik yang terjadi dalam proses leaching adalah perpindahan massa. Perbedaan konsentrasi dari konsentrasi tinggi ke konsentrasi yang lebih rendah dapat menyebabkan terjadinya transfer massa (Treybal, 1980). Semakin besar perbedaan dalam konsentrasi, semakin cepat transfer massa terjadi dan pencapaian kesetimbangan (Balladin et al., 1998).

Untuk Evaluasi pengaruh parameter proses (suhu, rasio enzim-substrat dan waktu ekstraksi) pada ekstraksi enzimatik menggunakan isolat enzim amobil rumen terhadap produksi minyak jahe dari pulp jahe telah dilakukan dan diperoleh kesimpulan bahwa faktor yang memiliki pengaruh terbesar adalah waktu ekstraksi. Pada suhu $60^{\circ} \mathrm{C}$, waktu ekstraksi 5 jam, $\mathrm{pH} 4$ dan $\mathrm{pH} 5$ serta enzim rumen yang digunakan pada rasio 1:5 maka akan diperoleh kondisi yang optimal dalam proses ektraksi. Pada $\mathrm{pH} 4$ dan $\mathrm{pH} 5$ minyak jahe yang diperoleh memiliki kandungan zingiberene yang masing-masing sebesar $21,56 \%$ dan $26,28 \%$. Pengurangan kandungan zingiberene akan terjadi bila ekstraksi dilakukan dalam waktu yang lebih lama (Handayani, 2018).

Mempertimbangkan manfaat jahe yang mengandung antioksidan tinggi yang berfungsi sebagai anti-inflamasi dan mencegah pertumbuhan tumor, perlu untuk mengekstraksi rimpang jahe untuk menentukan jumlah gingerol yang diekstrak. Tujuan penelitian adalah untuk menentukan kondisi terbaik, waktu yang tepat dan suhu dalam proses ekstraksi yang menghasilkan oleoresin jahe dan diharapkan bisa memberikan informasi tambahan tentang kondisi terbaik saat memproduksi hasil oleoresin pada jahe. Dari hasil penelitian diharapkan bisa meningkatkan nilai ekonomi tanaman, terutama untuk meningkatkan pendapatan para petani. Diduga hipotesis ini memiliki waktu yang tepat dan suhu yang optimal dalam proses ekstraksi untuk memproduksi hasil oleoresin jahe, dan diduga bahwa ada interaksi antara suhu dan waktu ekstraksi yang diperlukan untuk hasil dan kualitas oleoresin jahe.

\section{METODE PENELITIAN}

Bahan :

- 500 gram bubuk Jahe dari toko jamu "Dami" Semarang

- $\mathrm{CH}_{3} \mathrm{COOH}$ dan $\mathrm{NaOH}$ untuk mengontrol $\mathrm{pH}$ agar 6

- 8 liter Aquades

Metode

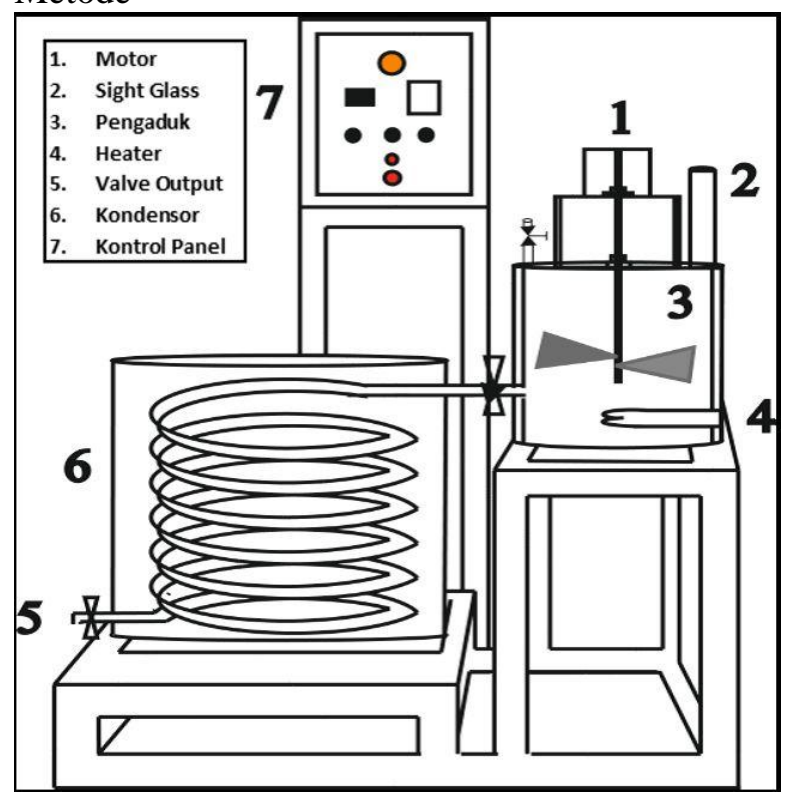

Gambar 1. Ekstraktor Berpengaduk

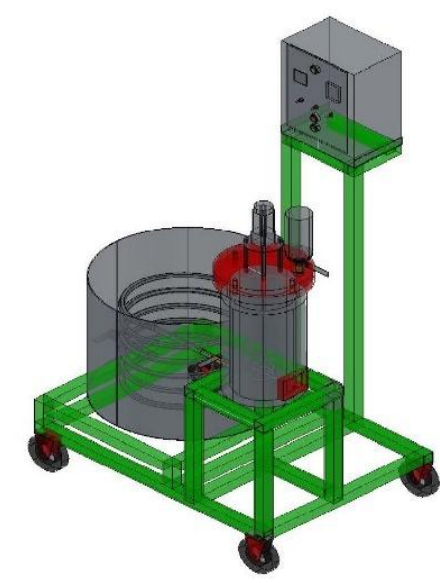

\section{Gambar 2. Ekstraktor Berpengaduk}

Variabel operasi selama penelitian terdiri dari variabel yaitu variabel kontrol dan variabel independen. 
Variabel kontrol

Variabel kontrol terdiri dari: (i) berat material: 500 gram / batch; (ii) kecepatan pengadukan: 20 rpm; (iii) jumlah pelarut: 8 liter; (iv) pH : 6 .

\section{Variabel independen}

Variabel independen terdiri dari: (i) suhu: $60^{\circ} \mathrm{C}$ $(-), 80^{\circ} \mathrm{C}(-)$ dan $100^{\circ} \mathrm{C}(+)$; (ii) waktu: 30 menit $(-)$ dan 60 menit (+).

\section{Prosedur Ekstraksi}

Ekstraksi dilakukan menggunakan ekstraktor yang diaduk (Gambar 1) yang dilengkapi dengan kondensor. Bahan-bahannya adalah 500 gram serbuk jahe yang dilarutkan dalam air sesuai dengan variabelnya. Kemudian, ukur $\mathrm{pH}$ campuran agar sesuai dengan variabel. Jika $\mathrm{pH}$ kurang asam maka $\mathrm{CH}_{3} \mathrm{COOH}$ ditambahkan dan jika $\mathrm{pH}$ kurang basa maka $\mathrm{NaOH}$ ditambahkan. Proses ekstraksi dilakukan selama 30 menit dan 60 menit dan sesuaikan kecepatan pengadukan ekstraktor hingga $20 \mathrm{rpm}$ dan suhu sesuai dengan variabel pada panel kontrol. Masukkan sampel melalui inlet, jika telah mencapai titik setel suhu, hitung waktu ekstraksi. Setelah proses ekstraksi adalah 30 menit, ekstrak hasilnya melalui output katup.

\section{Metode Analitik}

Metode analisis yang digunakan adalah dengan spektrofotometri, untuk menghitung hasil absorbansi dari spektrofotometer berdasarkan hukum Lambert Beer, akan diketahui tingkat gingerol yang dihasilkan.

\section{HASIL DAN PEMBAHASAN}

Berdasarkan pengamatan yang sudah dilakukan metode ekstraksi yang digunakan adalah ekstraksi berpengaduk dengan aquadest sebagai solvent tetap. Percobaan dilakukan dengan mengekstaksi jahe 500 gram dengan pelarut air pada $\mathrm{pH} 6$ dan jumlah pelarut 8 liter dengan suhu variable I $60^{\circ} \mathrm{C}$, variable II $80^{\circ} \mathrm{C}$, variable III $100^{\circ} \mathrm{C}$. Pengambilan sampel dilakukan pada menit ke-30 menit dan ke-60 menit. Setelah proses ekstraksi selesai, dilakukan uji spektrofotometri dengan panjang gelombang $465 \mathrm{~nm}$ untuk mengetahui kadar Gingerol yang terdapat dalam ekstrak jahe. Panjang gelombang diatur $465 \mathrm{~nm}$ sesuai dengan batas yang ditetapkan jika sampel berwarna kuning.
Tabel 1. Data Hasil Pengamatan

\begin{tabular}{cccccc}
\hline Var & Menit & Suhu & $\begin{array}{c}\text { Absorb } \\
\text { ansi }\end{array}$ & $\begin{array}{c}\text { Kadar } \\
(\mathrm{gr} / \mathrm{lt})\end{array}$ & $\begin{array}{c}\text { Kadar } \\
(\%)\end{array}$ \\
\hline \multirow{2}{*}{ I } & $\mathbf{3 0}$ & $\mathbf{6 0}$ & $\mathbf{1 , 6 4 4}$ & $\mathbf{1 0 , 4 9 7 7}$ & $\mathbf{1 6 , 7 9 6 3}$ \\
\cline { 2 - 6 } & $\mathbf{6 0}^{\prime}$ & $\mathbf{6 0}$ & $\mathbf{2 , 2 2 4}$ & $\mathbf{1 1 , 1 4 3 6}$ & $\mathbf{1 7 , 8 2 9 8}$ \\
\hline \multirow{2}{*}{ II } & $\mathbf{3 0}$ & $\mathbf{8 0}$ & $\mathbf{2 , 9 7 4}$ & $\mathbf{1 7 , 7 7 4 9}$ & $\mathbf{2 8 , 4 3 9 8}$ \\
\cline { 2 - 6 } & $\mathbf{6 0}$ & $\mathbf{8 0}$ & $\mathbf{3 , 1 5 7}$ & $\mathbf{1 7 , 7 9 4 9}$ & $\mathbf{2 8 , 4 7 1 8}$ \\
\hline \multirow{2}{*}{ III } & $\mathbf{3 0}$ & $\mathbf{1 0 0}$ & $\mathbf{3 , 4 5 2}$ & $\mathbf{1 7 , 9 7 8 9}$ & $\mathbf{2 8 , 7 6 6 2}$ \\
\cline { 2 - 6 } & $\mathbf{6 0}$ & $\mathbf{1 0 0}$ & $\mathbf{3 , 7 6 3}$ & $\mathbf{1 9 , 5 9 8 7}$ & $\mathbf{3 1 , 3 5 7 9}$ \\
\hline
\end{tabular}

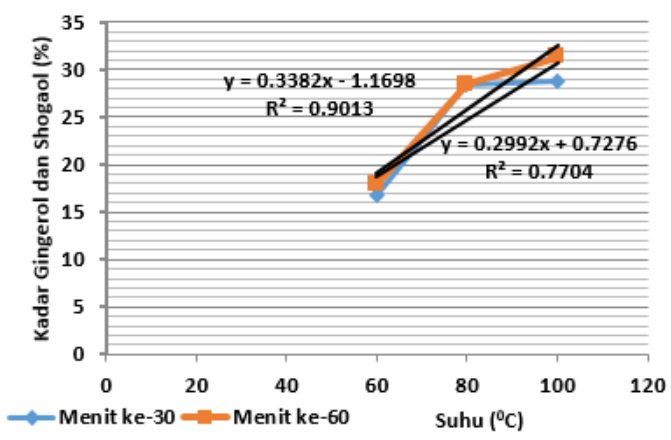

\section{Gambar 3. Grafik Pengaruh Suhu terhadap} Kadar Gingerol

Gambar 2 menunjukkan bahwa gingerol cenderung meningkat tetapi tidak signifikan seiring meningkatnya suhu dan lamanya ekstraksi. Berdasarkan grafik diatas dapat dilihat bahwa terjadi kenaikan kadar dari variable I sampai variable III dengan kadar Gingerol 16,7963\% 17,8298\% ; 28,4398\% $28,4718 \%$; 28,7662 ; dan 31,3579\%. Pada waktu ekstraksi 60 menit dan suhu ekstraksi $100^{\circ} \mathrm{C}$ merupakan hasil tertinggi kandungan gigerolnya yaitu sebesar $31,3579 \%$. Sedangkan kadar Gingerol pada suhu ekstraksi $60^{\circ} \mathrm{C}$ dan $80^{\circ} \mathrm{C}$ cenderung rendah. Sedangkan pada lama waktu ekstraksi 30 menit dengan suhu $60^{\circ} \mathrm{C}$ merupakan hasil terendah kandungan gingerolnya yaitu sebesar $16,7963 \%$. Hal ini diduga bahwa penyebab senyawa hasil ekstraksi senyawa fenolik seperti gingerol, zingeron dan shogaol hanya terekstrak sedikit karena suhu ekstraksi yang masih rendah. Pada jahe terdapat senyawa antioksidan yaitu senyawa gingerol, zingeron, dan shogaol. Laju proses ekstraksi berjalan lebih lama disebabkan karena suhu ekstraksi yang rendah. Jika lamanya waktu ekstraksi yang sama, Untuk mendapatkan yield ekstrak, TPC (Total phenolic content), dan yield senyawa phenolic yang lebih tinggi tetapi tidak signifikan maka suhunya juga harus semakin tinggi. Hal ini diduga bahwa penyebab kelarutan senyawa phenolic dalam pelarut 
semakin besar dikarenakan suhu yang tinggi. Jika suhu dan waktu ditingkatkan maka semakin besar difusi yang terjadi sehingga proses ekstraksinya juga semakin cepat. Namun dalam meningkatkan suhu operasi juga perlu diperhatikan, karena bisa menyebabkan kerusakan pada bahan yang sedang diproses jika suhunya terlalu tinggi. Gingerol merupakan komponen senyawa bioaktif utama dalam jahe yang tahan panas. Pada gambar diatas juga dapat dilihat bahwa absorbansi dan kadar sama sama mengalami kenaikan. Hal ini sudah sesuai dengan teori Lambert Beer, bahwa kadar dan absorbansi berbanding lurus.

\section{KESIMPULAN}

Pada percobaan pengaruh suhu terhadap kadar gingerol didapatkan kadar gingerol dan shogaol pada percobaan I hingga III yaitu $16,7963 \% \quad 17,8298 \%$; 28,4398\% $28,4718 \%$; 28,7662; dan 31,3579\%. Pada waktu ekstraksi 60 menit dan suhu ekstraksi $100^{\circ} \mathrm{C}$ merupakan hasil tertinggi kandungan gigerolnya yaitu sebesar $31,3579 \%$. Sedangkan kadar Gingerol pada suhu ekstraksi $60^{\circ} \mathrm{C}$ dan $80^{\circ} \mathrm{C}$ cenderung rendah. Sedangkan pada lama waktu ekstraksi 30 menit dengan suhu $60^{\circ} \mathrm{C}$ merupakan hasil terendah kandungan gingerolnya yaitu sebesar 16,7963\%.

\section{Ucapan Terimakasih}

Peneliti mengucapkan terima kasih kepada Ketua Program Studi Diploma III Teknik Kimia, Kepala Laboratorium DIII Teknik kimia Universitas Diponegoro dan teman-teman yang telah membantu dalam penelitian ini.

\section{DAFTAR PUSTAKA}

Agarwal, Walia S., Dhingra S., Khambay B.P., 2001. Insect growth inhibition, antifeedant and antifungal activity of compounds isolated/derived from Zingiber officinale Roscoe (ginger) rhizomes, Forum Teknik : 115-129.

Balladin, D, Headley, O, Chang-Yen, I and McGaw, D (1997) Extraction and evaluation of the main pungent principles of solar dried West Indian ginger (Zingiber officinale ROSCOE) rhizome. Renewable energy, 12, 125-130.

Balladin, DA, Headley, O, Chang-Yen, I and McGaw, DR (1998) High pressure liquid chromatographic analysis of the main pungent principles of solar dried West Indian ginger (Zingiber officinale Roscoe). Renewable Energy, 13, 531-536.

Banerjee, A., Dean Karlan, Jonathan Z., 2015. Six Randomized Evaluations of Microcredit: Introduction and Further Steps. Volume 7, pp. 1-21

Geankoplis, Christie J. 1993. Transport Processes and Unit Operations 3rd edition. Prentice-Hall : New Jersey.

Guenther, E., 1952. The Essential Oils Volume VI. D. Van Nostrand Company Inc., New York.

Handayani, Dwi., Amalia, Rizka., Endy Yulianto. M., Hartati, Indah., Murni. 2018. Determination of Influential Factors during Enzymatic Extraction of Ginger Oil Using Immobile Isolated Cow Rumen Enzymes. International Journal of Technology(2018) 3:455-463.

Hu, J., Guo, Z., Glasius, M, Kristensen, K., Xiao, L., Xu, X., 2011. Pressurized Liquid Extraction of Ginger (Zingiber officinale Roscoe) with Bioethanol: An Efficient and Sustainable Approach. Journal of Chromatography A, Volume 1218(34), pp. $5765-5773$

Onyenekwe, P. C.\& Hashimoto, S.(1999). The Composition of essential oil of dried Nigerian ginger (Zingiber Officinale ). Europcan Food Research and Technol.,209, 407-410.

Ramji, Divya., 2007. Isolation of Gingerol and Shogaols from Ginger and Evaluation of Their Chemopreventive Activity on Prostate Cancer Calls and Anti-Infalmmatory Effect on 12-Otetradecanoyl-Phorbol-13-Acetate (TPA)-Induced Mouse Ear Inflammation. New Brunswick, New Jersey

Treybal, Robert E.1981. "Mass Transfer Operations", 3th edition, Mc Graw Hill, Inc, New york.

Vernin, G and Parkanya, C (2004) Chemistry of ginger. In Babu, K. (ed.), Ginger: The genus zingiber. CRC Press, Boca Raton, FL, USA, pp. 87-180.

Williams, C.A., Lamprecht, E.D., 2008. Some commonly fed herbs and other functional foods in equine nutrition: a review. The Veterinary Journal Volume 178, pp. 21-31. 
